\title{
Multifarious networks in climate change research: scientists, policy makers and the public
}

\author{
Ana Delicado
}

\begin{abstract}
This paper explores the networks of collaborations that are formed in climate change research, both within the scientific community and with the political and social spheres. It draws on the case of climate change research in a particular national setting, Portugal.
\end{abstract}

Key Words: Climate change, science, scientists, networks.

$* * * * *$

\section{Introduction}

In the past few decades, climate change has gained an exceptional prominence not just as an environmental problem but also as a social and political issue and a new field of research. One of the most salient aspects of climate change science has been its collaborative nature. This has been particularly noticeable in the functioning of the Intergovernmental Panel on Climate Change (IPCC), which draws on the work of thousands of scientists from numerous disciplines and from all over the world, together with government experts and representatives. Collaboration here has a practical justification but also a symbolic one, in the sense that it confers legitimacy in a still contentious area. ${ }^{1}$

Since climate change is a global problem, much of the scientific research and policy making take place in the international arena, through large scale research projects and intergovernmental negotiation forums. However, since, on the one hand, this collective effort requires the involvement of national scientific systems and, on the other hand, local impacts demand specific responses, localised research does matter. National peculiarities regarding the political use of scientific advice and public engagement (both in science and in policy-making) also have a bearing on how this problem is dealt with.

This paper argues that this collaborative nature extends also to the level of national scientific systems. Typical of Mode 2 of Knowledge production, ${ }^{2}$ but probably more so than in other research fields, climate change science has spawned the creation of multiple alliances, within the scientific community as well as with the social and political sphere. As to the former, this can be measured by the amount of international projects and of inter-institutional and interdisciplinary collaborations. Regarding the later, this can be observed in the involvement of stakeholders, policy makers and members of the public in various stages of the 
research process. But how do these alliances work in practice? How are partners in the networks chosen? What roles do they play? What are the motivations behind extending the scientific process to other actors? What results are achieved?

This paper will strive to answer some of these queries. It is based on the analysis of climate change research in Portugal, supported by administrative data on research projects and interviews with scientists. It is part of an on-going research project in sociology of science.

\section{Networks within science}

The project that kick-started climate change research in Portugal - SIAM Climate change in Portugal: Scenarios, impacts and adaptation measures mimicked on a national scale the endeavours of IPCC reports, minus the political negotiations. Carried out between 1999 and 2002, it involved an extended team of 34 lead authors, 13 contributing authors and 15 reviewers, from 21 national institutions (universities, research centres, state laboratories, business companies) and eight foreign ones. The project covered a wide range of issues: current climate and climate scenarios, water resources, costal zones, agriculture, health, energy, forests and biodiversity, fisheries.

This first project pretty much set the tone for climate research in Portugal. In 2004, the main funding agency in Portugal, the Foundation for Science and Technology (FCT), part of the Ministry of Science, included climate change as one of the 70-plus scientific areas in its regular call for project proposals. In the following four calls, 86 projects concerning climate change were funded. These projects focused on very diverse subjects, from climate variation measurements to impact assessments in different fields (agriculture, forestry, socioeconomic activities, biodiversity), from mitigation technologies to adaptation strategies.

The institutions involved in these projects give us some idea of the field of climate change research in Portugal and the collaboration networks formed around this subject. These 86 projects were led by 43 different research centres, but involved in total 84 institutions. Three quarters of these projects were based on interinstitutional collaboration. Half of these collaborative projects involved just two partners, a third three institutions and a fifth between four and five research centres. One project brought together eight partners.

Some research centres clearly dominate this field. Two centres focusing on marine sciences have participated in eleven projects each, leading nine and eight of them, respectively. A forestry research centre has led four projects and participated in another three, as much as the leading climatology centre. Other institutions are highly sought after as partners, but lead no proposals, such as en engineering centre and a fisheries institute.

Considering the relationships between institutions in these projects through a social network analysis, ${ }^{3}$ represented in Image 1 , reveals that the density of collaborations in this field is not very high $(0.053) .{ }^{4}$ Some pairs of institutions 
collaborate preferentially among each other (visible in Image 1 through thicker links between nodes). Three institutions are at the core of this network, with high values of betweeness centrality (over 500): $:^{5}$ an Earth and Space Sciences research centre, another in Marine Sciences and another in Agricultural Sciences.

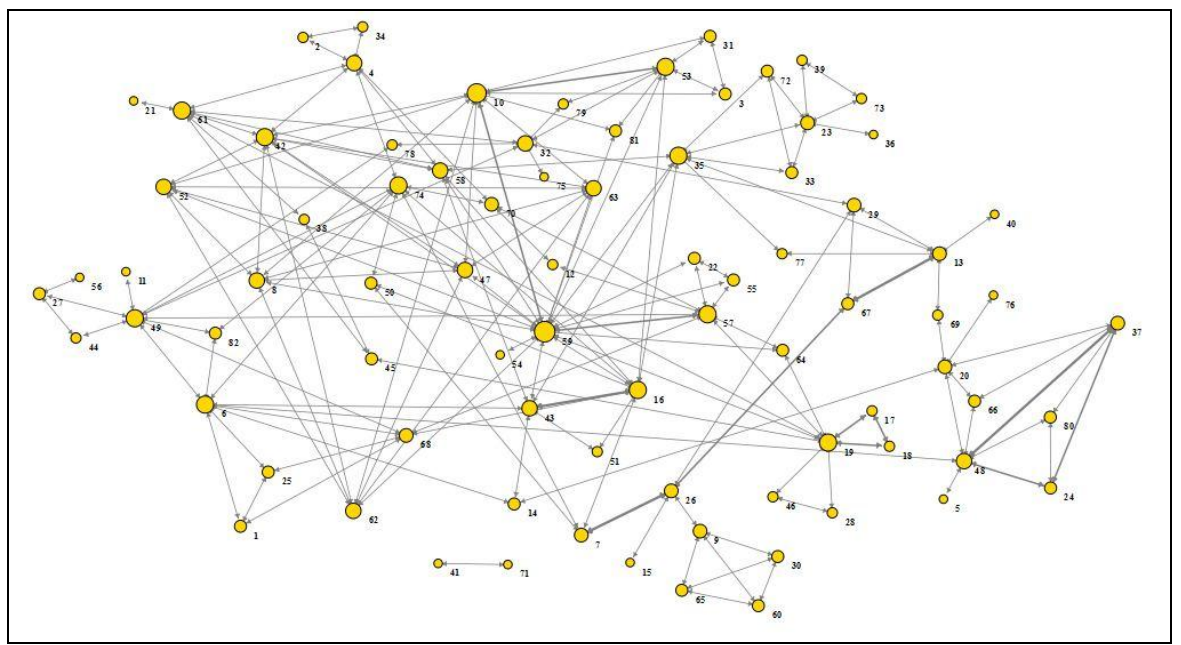

Image 1 Network of interinstitutional collaborations

Interviews with some of the principal investigators in these projects yield information on the mechanisms and motivations through which these interinstitucional networks are formed.

First, teams are built on previous personal knowledge, rather than purely scientific reasons

There's a small community, a small network, people who are used to work together and have just finished a project and would like to continue to work on the same subject (...) We have to select teams with whom one knows one works well. With whom one knows we can achieve good results (oceanographer)

Second, the resources possessed by institutions are also a key factor for forging partnerships

In our case we sometimes have a logistical motivation. For instance, the Institute... has access to boats, has access to instrumentation. (oceanographer) 
The policy set by the funding agency plays a role as well in stimulating networks:

the Ministry, through the Foundation for Science and Technology encourages it [partnerships] and I agree (...) synergies must exist, equipment, data (engineer).

However, several PI also mention the obstacles in working in collaboration with Portuguese institutions:

sometimes in national projects the cooperation is more uncertain, perhaps due to the weakness of national groups. It's a Portuguese idiosyncrasy, the cooperation is not so good (...) It's very variable and the small size of the country sometimes doesn't allow us to do something (forestry researcher)

Interdisciplinary collaborations are at the heart of climate change research. The complexity of this issue, but also the wide array of areas over which it has potential impacts and consequences, call for the constitution of multi-skilled teams. ${ }^{6}$

Based on the analysis of the same 66 FCT funded projects in collaboration, 47 included research centres from different disciplines. The pattern of interdisciplinary links can be seen on Image 2. The most frequent relationships are established between Earth and Space Sciences (mostly climatology) and Engineering or Agricultural Sciences. There is also frequent collaboration between Agricultural Sciences, Marine Sciences and Engineering.

Data collected from the interviews underlines the advantages brought by interdisciplinary collaboration

sometimes we need to give more complementarity to the teams. We work mainly on the physical oceanography component, they work on the biology part (oceanographer)

but also the central role played by climatological models in projects pertaining other scientific disciplines

this is a research centre that focus on agriculture, there is also a small group connected to hydraulics and hydrology, with whom I also work, all these people need climate information and ask me for it. They tell me they need precipitation series or temperature series, and I tell them I can give them also series generated by future climate models. They don't have the knowledge nor the 
interest in doing research in this field, they just need outputs to include in their models or in their activities (climatologist)

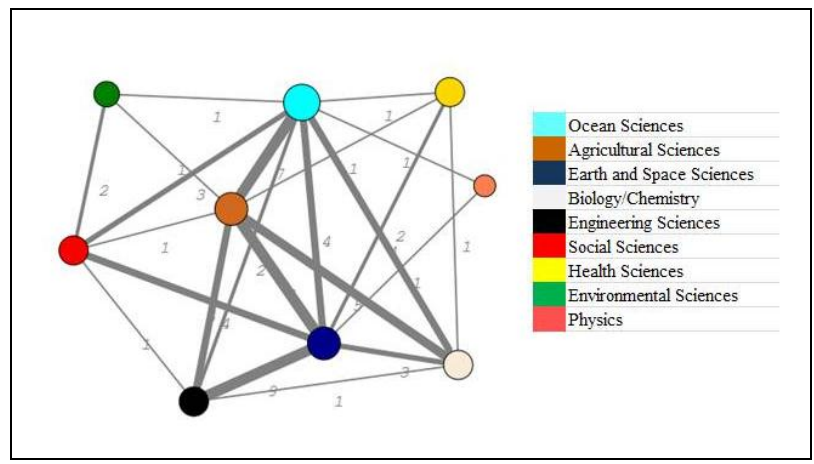

Image 2 Network of interdisciplinary collaborations

Finally, the international dimension cannot be overlooked. Ten of the FCT funded projects involved partners from other countries and several researchers take part in other international projects. Most of these are EU funded, so forming consortia with several countries is mandatory. International collaboration projects bring together partners with specific skills

our Spanish and French partners, we knew them already from other areas. The Spanish is an expert on remote detection, on satellite images, the French is from INRA, the agricultural research institute, he's an expert on vegetation (...) I like their approach (...) a really good team. The Italians were recommended to us and a Greek as well. (...) we had to have a minimum number of partners (geostatistician)

or with similar disciplinary backgrounds working on different regional contexts

I coordinate a project (...) in the Mediterranean with Portuguese, Spanish and Greeks (...) the fundamental idea was to network. The project didn't have a lot of money for new observations but it had the idea of bringing us together, of us working together in similar ecosystems, since we also work in similar areas of research (oceanographer)

International collaboration can also be motivated by the need to share scarce resources: 
to work in Antarctica, international cooperation is fundamental. There are no teams working in isolation. One of the main issues is logistics and to Portugal that is fundamental. We can't reach Antarctica because we don't have the logistics to get there. We have to use other countries' logistics (geographer)

On the whole, participation in international projects is seen as unreservedly positive, an opportunity to learn, expand horizons and generate scientific collaboration:

for us here in Portugal [the benefit] was opening up to other scientific communities, because these projects involve several countries, not just the coordinator, we start to know, we start to have relations with other colleagues. (...) we have this relationship, we write articles together. It was mainly this opportunity to open up, to know what others are doing, to learn new things, these projects were very useful.' (climatologist)

\section{Networks between science and policy}

Policy decisions on mitigation and adaptation measures cannot be but based on scientific evidence and advice, in a dynamics in which "natural knowledge and political order are co-produced through a common social project that shores up the legitimacy of each'. ${ }^{7}$ The role of scientific advice in policy decision is a much discussed issue and in climate change it is utterly unavoidable. ${ }^{8}$

Although scientists sit at advisory councils and have a say on national plans and legislation, most of the policy in Portugal is strongly influenced by the European Union, since Environment is one of its areas of competence.

The co-production of research between political actors and scientists is very uncommon. Most public support comes from general funding for research from the Ministry of Science, not from the ministries that oversee areas that experience climate change impacts (agriculture, fisheries, forestry, health). Some ministries have their own research bodies (state laboratories, research units) but are scarcely involved in scientific projects in the area of climate change. For instance, the Meteorological Institute (under the authority of the Ministry of Science) is one of the nine existing state laboratories and it took part in just four of the 86 FCT funded projects.

The level of involvement of local authorities is ever lower. Just a handful of local authorities have commissioned and funded research on the local impacts of climate change, in order to prepare strategic adaptation plans. Just one FCT funded project (in agricultural sciences) had a municipality as participating institution and 
just one of the interviewees mentioned the participation of a few local councils in a European funded project.

It was an excellent work on all levels. National work, of our centre and five more teams, local municipalities, all that. It was very good, it really impressed ESA, the only country... at the end of the day, it was the only country that carried it through, it was us (geostatistician)

\section{Networks between science and society}

Dealing with climate change requires alliances between scientists and policy makers but also citizen participation, through networks that involve NGOs, business companies and communities. ${ }^{9}$ European and national regulations have been establishing mandatory hybrid forums for managing environmental risk, in which citizens, experts and policy makers interact (participatory environmental assessments, public hearings and debates, consensus conferences, scenario workshops). ${ }^{10}$

R\&D endeavours also would benefit from taking into consideration social needs and concerns, local knowledge and lay expertise; that is to say, to involve citizens in the definition of research questions, in the process of data collection or in the design and implementation of technical solutions. ${ }^{11}$ Mitigation and adaptation to climate change requires not just changes in the practices of governments and business companies but also in individual behaviour and consumption, ${ }^{12}$ that can only be brought about by "creating shared frames of reference and opportunities for shared action"13 and not just by providing scientific information ${ }^{14}$ and advertising new eco-friendly technologies.

In Portugal, the level of formal participation in $R \& D$ endeavours by the private sector (profit and non-profit) is quite low. Out of the 84 participating institutions in the 86 FCT funded projects, just three were business companies, one a federation of business associations and another a non-governmental organisation (an archaeology club). The weak involvement of business companies is explained not just by the less-applied nature of research in this field but also by the structure of the Portuguese scientific system (the business sector has low R\&D funding and performing rates). But this almost certainly hinders the use of research results for developing innovative processes or products aimed at climate change mitigation or adaptation.

As to citizen participation in research, it is almost unheard of. There is only one project that aimed to tap into lay knowledge, by studying 'traditional irrigation systems and how they respond to unusual climate conditions in order to forecast problems and draw alleviation strategies'. ${ }^{15}$ 
Links between science and society are thus limited to top-down approaches. The majority of projects foresee the dissemination of results to the wider public and some research teams are involved in public understanding of science activities regarding climate change. One such initiative consisted of providing secondary schools with weather monitoring devices, training teachers and students on how to read them and to send the results back to scientists, in order for them to feed a forecast model:

It was technical-scientific education not only on a conceptual level but also on a practical level. (...) people were being educated with the correct ideas about the issue and started to practice by doing their own observations and seeing that these observations served a useful purpose (...) this project was very useful because it raised awareness of this issue (climatologist)

\section{Final remarks}

This paper has striven to describe briefly the networks of collaborations that have been formed around climate change research in Portugal. The main point that emerges from this succinct analysis is that although cooperation is rife in the scientific community, both between institutions, disciplines and even international partners, stimulated both by scientific and strategic needs, connections to the social and political sphere are still weak. The development of epistemic communities and the co-production of knowledge in climate change seems still a long way away.

Among other things, what this paper leaves out is the conflictual nature of some relationships. Research teams also compete for limited resources (funding, prestige), different social actors struggle for influence over policy, experts claim the superior legitimacy of science over other forms of knowledge.

\section{Notes}

${ }^{1}$ Sonja Boehmer-Christiansen. 'Global climate protection policy: the limits of scientific advice, Part 1.' Global Environmental Change 4, no. 2 (June 1994): 140159; Mike Hulme. Why We Disagree About Climate Change: Understanding Controversy, Inaction and Opportunity. (Cambridge: Cambridge University Press, 2009); Clair Gough and Simon Shackley. 'The Respectable Politics of Climate Change: The Epistemic Communities and NGOs.' International Affairs Vol. 77, no. 2 (2002): 329-346.

${ }^{2}$ Andrew Jamison. 'Climate change knowledge and social movement theory.' Wiley Interdisciplinary Reviews: Climate Change 1, no. 6 (November 2010): 811823. 
${ }^{3}$ Performed using Socnetv software.

${ }^{4}$ This value varies between 0 and 1 and concerns the ratio between the number of existing links (293) and the number of possible links (5860).

${ }^{5}$ Betweeness centrality is measured by the number of shortest paths from all vertices to all others that pass through a node.

${ }^{6}$ Myanna Lahsen. 'The Social Status of Climate Change Knowledge: an editorial essay.' Wiley Interdisciplinary Reviews: Climate Change 1, no. April (2010. 7 Sheila Jasanoff and Brian Wynne. 'Science and decision-making.' In Human choice and climate change, v.1, edited by Steve Reiner and Elisabeth M. Malone, 1-87. (Coloumbus: Bettellle Press, 1998), 16

${ }^{8}$ Reiner Grundmann. 'Climate change and knowledge politics.' Environmental Politics 16, no. 3 (June 2007): 414-432.

${ }^{9}$ Tim O'Riordan et al. 'Institutional frameworks for political action', in Human Choice and Climate Change - vol. 1 The Societal Framework, ed. S. Rayner and E. L. Malone, (Columbus: Batelle Press, 1998), 345-440; Gough and Shackley. 'The Respectable Politics...'.

${ }^{10}$ Bernd Kasemir, Carlo C. Jaeger and Jill Jäger. 'Citizen participation in sustainability assessments.' In Public participation in sustainability science, edited by Bernd Kasemir, Carlo C. Jaeger, Jill Jäger, and Mathew T. Gardner, 3-36. (Cambridge: Cambridge University Press, 2003).

${ }^{11}$ Eva Heiskanen. 'Encounters between Ordinary People and Environmental Science - A Transdisciplinary Perspective on Environmental Literacy.' The Journal of Transdisciplinary Environmental Studies 5, no. 1-2 (2006): 1-13.; F. M. Lynn, 'Community-Scientist Collaboration in Environmental Research.' American Behavioral Scientist 44, no. 4 (2000): 649-663.

${ }^{12}$ E. Tompkins and Neil W Adger. 'Defining response capacity to enhance climate change policy.' Environmental Science \& Policy 8, no. 6 (December 2005): 562-571.

${ }^{13}$ S. Rayner and E. L. Malone. Human Choice and Climate Change - vol. 4 What have we learned? (Columbus: Batelle Press, 1998), 13

${ }^{14}$ Paul Kellstedt, Sammy Zahran, and Arnold Vedlitz. 'Personal Efficacy, the Information Environment, and Attitudes Toward Global Warming and Climate Change in the United States.' Risk Analysis 28, no. 1 (2008): 113-126.

${ }^{15}$ 'CESAM-TRADWATER', viewed 28 May 2011, http://www.cesam.ua.pt/index.php?menu=82\&tabela=projectosdetail\&projectid= 136\&language $=$ eng 


\section{Bibliography}

Boehmer-Christiansen, Sonja. 'Global climate protection policy: the limits of scientific advice, Part 1.' Global Environmental Change 4, no. 2 (June 1994): 140159.

Gough, Clair and Simon Shackley. 'The Respectable Politics of Climate Change: The Epistemic Communities and NGOs.' International Affairs Vol. 77, no. 2 (2002): 329-346.

Grundmann, Reiner. 'Climate change and knowledge politics.' Environmental Politics 16, no. 3 (June 2007): 414-432.

Heiskanen, Eva. 'Encounters between Ordinary People and Environmental Science - A Transdisciplinary Perspective on Environmental Literacy.' The Journal of Transdisciplinary Environmental Studies 5, no. 1-2 (2006): 1-13.

Hulme, Mike. Why We Disagree About Climate Change: Understanding Controversy, Inaction and Opportunity. (Cambridge: Cambridge University Press, 2009).

Jamison, Andrew. 'Climate change knowledge and social movement theory.' Wiley Interdisciplinary Reviews: Climate Change 1, no. 6 (November 2010): 811-823.

Jasanoff, Sheila and Brian Wynne. 'Science and decision-making.' In Human choice and climate change, v.1, edited by Steve Reiner and Elisabeth M. Malone, 1-87. (Coloumbus: Bettellle Press, 1998).

Kasemir, Bernd, Carlo C. Jaeger and Jill Jäger. 'Citizen participation in sustainability assessments.' In Public participation in sustainability science, edited by Bernd Kasemir, Carlo C. Jaeger, Jill Jäger, and Mathew T. Gardner, 3-36. (Cambridge: Cambridge University Press, 2003).

Kellstedt, Paul Sammy Zahran, and Arnold Vedlitz. 'Personal Efficacy, the Information Environment, and Attitudes Toward Global Warming and Climate Change in the United States.' Risk Analysis 28, no. 1 (2008): 113-126.

Lahsen, Myanna. 'The Social Status of Climate Change Knowledge: an editorial essay.' Wiley Interdisciplinary Reviews: Climate Change 1, no. April (2010).

Lynn, F. M. 'Community-Scientist Collaboration in Environmental Research.' American Behavioral Scientist 44, no. 4 (2000): 649-663. 
O'Riordan, Tim et al. 'Institutional frameworks for political action', in Human Choice and Climate Change - vol. 1 The Societal Framework, ed. S. Rayner and E. L. Malone, (Columbus: Batelle Press, 1998), 345-440.

Rayner, S. and E. L. Malone. Human Choice and Climate Change - vol. 4 What have we learned? (Columbus: Batelle Press, 1998).

Tompkins, E, and Neil W Adger. 'Defining response capacity to enhance climate change policy.' Environmental Science \& Policy 8, no. 6 (December 2005): 562571.

Ana Delicado is a Research Fellow at the Institute of Social Sciences of the University of Lisbon. She has a $\mathrm{PhD}$ in sociology and specialises in the social studies of science. Her current research concerns scientific societies and the climate change research community. ana.delicado@ics.ul.pt 